\title{
НЕКОТОРЫЕ ВОПРОСЫ ПРАВОВОЙ ОХРАНЫ ИНДИВИДУАЛЬНОГО ХУДОЖЕСТВЕННОГО СТИЛЯ
}

\section{SOME ISSUES OF LEGAL PROTECTION OF AN INDIVIDUAL ARTISTIC STYLE}

\section{Bogatova}

Summary. This article discusses some issues of legal protection of an individual artistic style. It is determined that the current legislation provides legal protection to the work of art itself as a result of intellectual activity within the framework of copyright, while ideas and designs are not recognized as subject matter and are not subject to protection. In contrast, patent law protects the result of intellectual activity as an idea (invention). The legal protection of an individual artistic style thus constitutes a partial reception of patent right into copyright.

The author comes to the conclusion that the protection of an individual artistic style can be carried out through giving it a conditional objective form of an individual-stylistic description. Considering a work of art as a product of creative processing of an individual artistic style, the compilation of an individual artistic style, thereby, will prohibit the reception of this style by other authors without the consent of the copyright holder.

Keywords: individual artistic style, copyright, patent law, copyright works, authors 'rights, protection of copyright objects, violation of artists' copyright, legal object of individual artistic style.

\author{
Богатова Ирина Александровна \\ Аспирант, Московский финансово-юридический \\ университет \\ ira010187@rambler.ru
}

Аннотация. В настоящей статье рассматриваются некоторые вопросы правовой охраны индивидуального художественного стиля. Определено, что действующее законодательство предоставляет правовую охрану самому художественному произведению как результату интеллектуальной деятельности в рамках авторского права, при этом идеи и замыслы не признаются правообъектными и охране не подлежат. В рамках патентного права, напротив, охраняется результат интеллектуальной деятельности в качестве идеи (изобретение). Правовая охрана индивидуального художественного стиля, таким образом, представляет собой частичную рецепцию патентного права в авторское право.

Автор приходит к выводу, что охрана индивидуального художественного стиля может осуществляться через придание ему условной объективной формы индивидуально-стилистического описания. Рассматривая художественное произведение как продукт творческой переработки индивидуального художественного стиля, составление индивидуального художественного стиля, тем самым, воспретит рецепцию данного стиля другими авторами без согласия правообладателя.

Ключевые слова: индивидуальный художественный стиль, авторское право, патентное право, авторское произведения, права авторов, охраноспособность объектов авторского права, нарушения авторских прав художников, правообъектность индивидуального художественного стиля.

Наиболее распространенный способ нарушения авторских прав художников заключается в непосредственном использовании произведений, чаще всего - для коммерческих целей, при чем в таких случаях обыкновенно нарушается не только исключительное право, но и неимущественные права автора. Встречаются и случаи регистрации художественных произведений в качестве товарных знаков или знаков обслуживания без разрешения правообладателей.

Более сложным случаем с точки зрения правовой охраны, является неправомерная переработка произведения. В отличие от патентного права на изобретение, авторское право не предоставляет защиты идеям и замыслам, поэтому доказать факт переработки можно только экспертным путем, при чем отнюдь не с абсолютной достоверностью и существенной долей субъективного суждения эксперта. Производство такой 
экспертизы связано с значительными затратами и организационными сложностями, поэтому для отдельных авторов такая защита оказывается актуально недоступной.

Для авторов, работающих в области кукольного искусства и иного «хэнд-мэйда» индивидуальный художественный стиль (далее - ИХС) представляет особую ценность в силу специфики данного вида творчества. Однако, защита ИХС сталкивается с фундаментальными сложностями: во-первых, авторское право, как уже отмечалось выше, не предоставляет охраны идеям, замыслам и концепциям; во-вторых, интеллектуальное право не признает правообъектность произведений, не имеющих объективной материальной формы; в-третьих, доказательство стилистической однородности («переработки стиля») возможно только путем дорогостоящей и субъективной экспертизы.

Изобразительное искусство, в свою очередь, включает в себя множество различных видов, которые можно классифицировать как: фотоискусство, живопись, графика, декоративно-прикладное искусство дизайн, граффити, каллиграфия, скульптура, архитектура и ряд других [2, с. 54]. Одновременно следует обратить внимание на то, что определения понятия живописи и скульптуры, современное законодательство Российской Федерации не содержит.

На примере скульптуры можно наглядно понять существующие правовые коллизии. Авторские права на скульптуру охраняются законом, но при этом в законодательстве отсутствует определение скульптура, а также отсутствуют отличительные признаки одного изделия от другого. В результате, к скульптуре может быть в полной мере отнесена мягкая игрушка с металлическим каркасом и подставкой, которая чисто визуально напоминающая постамент. В свою очередь, в том случае, если материалом, для создания скульптуры, стал поролон, то её могут причислить к мягкой игрушке.

Аналогичная ситуация, связана и с картинами. В частности, если рассмотреть некоторые настенные украшения, например, вышитые картины, батик, гобелены, тканые картины и т.д., то не очень понятно, к какой группе изделий их относить. Возникает двусмысленность: с одной стороны, это текстильные изделия, которые естественно не подпадают под правовую защиту, но с другой это картины, а значит, они могут и должны охраняться законом как предметы изобразительного искусства.

Более того, если, например, гобелен или тканая картина изготовлена художником, то ее принадлежность к произведениям искусства не вызывает сомнений, в отличие от тождественного гобелена, изготовленного автоматическим станком - хотя бы и в одном экземпляре.
Но приобретатель картины не знает и не может знать со всей определенностью способ изготовления произведения - в результате, приобретатель может приобрести несуществующее исключительное право.

Предмет иного пробела законодательства составляет регулирование технологических аспектов деятельности художника. Действительно, очень часто как технологические приемы, так и особый художественный стиль составляют существенную часть произведения, делают возможным его появление в сущей форме, определяют художественное воздействие на человека. Если в области промышленности закон охраняет изобретения, промышленные образцы, полезные модели и даже ноу-хау, то аналогичные объекты в сфере художественного творчества никак не охраняются, хотя и существуют объективно, а их ценность художниками не оспаривается.

Действительно, в настоящее время художественное творчество становится все более технологичным, художники используют не только вычислительную технику, но и устройства, позволяющие тиражировать идентичные произведения не только живописи, но и скульптуры (3D-печать). В этой связи структура правовой реальности художественного творчества, никак не умаляя собственно творческого содержания, сближается со структурой правой реальности промышленности: в деятельности художника несложно выделить аналоги изобретения, полезной модели, промышленного образца и ноу-хау. К сожалению, эти аспекты художественного творчества вообще не учитываются гражданским законодательством, без всяких к тому оснований, по нашему мнению, умаляя объективно присущие художнику средства правовой защиты.

Спорные ситуации, могут возникать, в результате описанной выше двусмысленность или двойственности в квалификации, тех или иных видов изделий.

В связи с этим, в рамках исследования, и непосредственно в данной статей предлагается определять понятия живопись и скульптура, следующим образом:

Живопись - это форма изобразительного искусства или способ художественного отображения реальной действительности, сущность которого заключается в создании с помощью красок, наносимых на конкретную поверхность живописных полотен и картин.

Скульптура - это форма изобразительного искусства или способ художественного отображения реальной действительности, сущность которого заключается в создании объемных трехмерных форм, выполнение которых осуществляется из твердых или пластичных материалов. 
Произведения, как живописи, так и скульптуры отнесены действующим законодательством к результатам интеллектуальной деятельности. В этой связи они и относятся, и признаются традиционными объектами авторского права, так как, согласно ст. 1225 ГК РФ, в список включены, в том числе произведения науки, литературы и искусства. Кроме того, на основании пункта 1 ст. 1259 ГК РФ данный перечень отнесен к объектам авторского права. Особенностью здесь является утверждение о том, что для отнесения того или иного произведения к объектам авторского права не влияет ни назначение, ни его достоинства, ни способы его выражения.

«Парижская конвенция по охране промышленной собственности» (1883 г.) [3], служит моделью для дальнейшего развития данного вида охранных прав, заключенного между различными странами. Данный документ представляет собой универсальный международный договор по охране результатов интеллектуальной деятельности.

В свою очередь, первым международным договором по защите авторских прав является «Бернская конвенция по охране литературных и художественных произведений» (1886 г.) [4]; которая представляет собой свод правил, которыми продолжают пользоваться и поныне. Основной смысл конвенции заключен во взаимном признании авторского права всеми странами-участницами. В настоящий момент число участников конвенции уже составляет 164 страны, в том числе и Российская Федерация

Российская Федерация активно принимает участие во многих международных соглашениях в качестве полноправной участницы, касающихся отношений сферы интеллектуальной собственности.

Для того, чтобы прийти к достижению цели, связанной с повышением эффективности правового регулирования вопросов, относящихся к интеллектуальной собственности, считаем необходимым:

- во-первых, законодательно расширить объекты правовой защиты художественного творчества, дополнив их аналогами изобретения, полезной модели, промышленного образца и ноу-хау,

- во-вторых, расширить задачи Роспатента, либо иного государственного органа, который будет на то уполномочен и закрепить за ним процедуру уведомительной и добровольной государственной регистрации произведений живописи и скульптуры в качестве объектов интеллектуальной собственности по аналогии с программным обеспечением путем депонирования их образов в реестре объектов интеллектуальной собственности.
В этом случае существенным образом будет расширены возможности депонированного произведения живописи или скульптуры, это связано с тем, что, учитываться станет не только сам факт создания произведения, но и его художественное исполнение, а также индивидуальный художественный стиль написания и его отличительные черты

Всё это может стать основой для формирования новой системы охраны произведений живописи и скульптуры и оказать неоценимую помощь при защите прав автора.

Таким образом, индивидуальный художественный стиль опосредует диалектическое единство творческого начала личности художника и его творческий метод в широком понимании - от технических навыков до навыков художественного отражения объективной и субъективной действительности. В этом заключается источник проблемы правообъектности ИХС: будучи своего рода «метаформой», ИХС не имеет конкретного референта, не является собственно произведением, четко отграниченным от других произведений.

При этом, ИХС может быть скопирован иным художником, обладающим достаточными для этого техническими навыками: такой «контрафактный» ИХС будет неподлинным, по сути своей - фальшивым продуктом отнюдь не творческой, а технологической деятельности. Более того, примеры копирования ИХС можно обнаружить в технико-математических (пока еще) экспериментах в области глубокого машинного обучения искусственных нейронных сетей. Разумеется, понятие «творчество» в общепринятом смысле никак не распространяется на функционирование компьютера. Между тем, именно фальшивость ИХС и позволяет, в конечном итоге, выявить компьютерную подделку, «мимикрирующую» под творчество конкретного художника.

Как следует, в частности, из ст. 1270 ГК РФ, объектом правовой охраны результатов интеллектуальной деятельности является именно произведение автора, а не «художественная метаформа», даже если последняя бесспорно является продуктом творчества художника. Пронизывая различные произведения автора, ИХС, как тонкая творческая материя, очень трудно поддается объективации - при том, что для художников, искусствоведов и коллекционеров объективность и художественная ценность ИХС не составляет никаких сомнений.

Таким образом, необходимым условием правообъектности ИХС является его объективация и обособление от иных форм, метаформ и произведений. Такая объективация осуществляется двояко, в зависимости от вида правоотношений, возникающих по поводу ИХС. Для от- 
ношений «имущественного» типа характерна абсолютность, то есть охрана от любых притязаний любых лиц. Обязательственные отношения, напротив, всегда являются относительными. Иначе говоря, можно выделить абсолютную и относительную правообъектность индивидуального художественного стиля.

В рамках действующего гражданского законодательства Российской Федерации абсолютная правообъектность ИХС не возникает сама по себе, но конструируется посредством создания специального произведения - «индивидуально-стилистического описания» (далее-ИСО).

Индивидуально-стилистическое описание представляет собой самостоятельное комплексное произведение, содержащее следующие существенные элементы:

- развернутое дискурсивное описание художественного метода, включающее отражение мироощущения художника;

- эскизы основных элементов ИХС как метасимволов и их описание («легенда») со ссылками на референты, приведенные в развернутом дискурсивном описании («художественные параформулы»);

- примеры художественной реализации основных элементов ИХС.

В системной взаимосвязи норм, содержащихся в п. 7 ст. 1259 ГК РФ и п. 2 ст. 1270 ГК РФ, любое использование основных элементов ИХС, содержащихся в индивидуально-стилистическом описании как самостоятельном художественном произведении, потребует согласия (лицензии, заключения лицензионного договора) с правообладателем ИСО, которым носитель стиля становится вследствие авторства ИСО.

Разумеется, создание ИСО не решает проблему правообъектности ИХС в полном объеме - для этого представляется необходимой новация ч. 4 ГК РФ путем ее дополнения нормами об ИХС как результате интеллектуальной деятельности. Однако, ИСО создает правовую основу для защиты ИХС в судебном порядке, создавая легально допустимый предмет судебного спора. Одновременно, судебный контроль позволит актуально исключить или серьезно воспрепятствовать возможным случаям злоупотребления правом путем создания очень широких ИСО, охватывающих «все, что угодно».

Модель правовой охраны ИХС через авторство ИСО создает основу для юридической защиты стиля, самостоятельно выработанного художником в рамках полной свободы творчества и творческого цикла. Однако, в случае создания служебных произведений и произведений по авторскому заказу, по существу - в рамках относи- тельного правоотношения обязательственного характера, такая схема может оказаться неприменимой или слишком сложной. В случае осуществления творческой деятельности в рамках обязательственных правоотношений ключевым элементом «защитного щита» индивидуального художественного стиля может выступать договор авторского заказа, который определяет технические параметры будущего произведения, характеризует жанр, назначение, объем, ИХС и другие особенности творческого замысла; устанавливает сроки и форму представления работы заказчику, порядок устранения замечаний.

Вопрос о пределах охраны ИХС является неоднозначным с точки зрения нахождения баланса между общественным и частным интересом. Действительно, если автор умышленно или по небрежности составит ИСО настолько общее, что окажется включающим в себя любые иные индивидуальные художественные стили, то дальнейшее художественное творчество окажется невозможным, что очевидным образом нарушает общественный интерес. Отсюда следует, во-первых, необходимость законодательного установления детальных требований к ИСО, а во-вторых, закрепление исключительно судебного порядка рассмотрения любых споров по поводу ИХС, при этом назначение искусствоведческой экспертизы должно быть обязательным. Рассматривая такой спор суд должен удостовериться в надлежащем характере спорных ИСО, включая вопрос об уникальности и специфичности определяемых спорными ИСО индивидуальных художественных стилей.

По своей природе ИХС носит личный характер, будучи неразрывно связан с психической деятельностью художника. Разумеется, это не препятствует копированию ИХС, что приводит к появлению неподлинных произведений, основанных на тонкой лжи, лицемерии и недобросовестности плагиатора стиля. В результате и само произведение приобретает несколько фальшивый характер. В этой связи представляется необходимым установление законодательного запрета на переход исключительного права на ИСО к другим лицам, помимо автора, а также недопустимость ИСО в качестве предмета договора авторского заказа или служебного произведения.

Основная доктринальная сложность состоит в том, что предметом ИСО, как и договора авторского заказа является произведение, которое еще только предстоит создать, то есть на момент составления ИСО или заключения договора произведения отсутствуют, и о качестве и содержании создаваемого произведения можно говорить лишь с известной долей вероятности. По мнению профессора В.А. Дозорцева, договоры на создание произведений (так называемые договоры заказа) можно условно отнести к числу авторских: при их заключении еще нет самого объекта авторского права - произведе- 
ния, нет, поэтому и обладателя авторских прав и самого субъективного авторского права в целом. Такие договоры являются договорами подрядного типа, специфика которых заключается в творческом характере выполняемой по договору работы [5, с. 40].

В то же время, как справедливо отметил профессор А.Е. Суханов, договоры заказа в «чистом виде» практически не встречаются. Они предусматривают также и последующее использование произведения, поэтому такие соглашения о создании и последующем использовании произведения следует относить к числу авторских [6, с. 257].

В случае защиты ИХС, речь как раз и может идти о договоре заказа в «чистом виде», при этом ИСО представляет собой декларацию автора по отношению к самому себе Такие декларации не порождают и не изменяют субъективные права и обязанности, относясь к внутрипсихической, а не социальной жизни человека, однако, образуют юридический факт, который может иметь правовые последствия.

Таким образом, одним из способов, защиты именно ИХС является включение в состав договора авторского заказа индивидуально-стилистического описания. На начальном этапе, до появления реальных результатов от действующей судебной практики данный вид заключенных договоров может иметь формальный характер.

Наиболее простой способ защиты ИХС заключается в возложении на аккредитованные организации, осуществляющие коллективное управление авторскими правами (ст. 1242 ГК РФ) или на саморегулируемые организации авторов коммерческих функций в отношении художественных произведений. Например, заключив с Союзом художников договор, на то или иное авторское произведение, автор указывает в договоре ключевые параметры своего индивидуального художественного стиля (ИСО), тем самым включая в орбиту защиты своего ИХС договорное право.

В договоре авторского заказа можно установить, что авторские права и ИХС сохраняются за автором, но при этом существует коллективная их защита уже от лица «заказчика». В качестве заказчика могут выступать аккредитованные организации по коллективному управлению правами, творческие союзы, а также иные СРО.
Для охраны своих прав автор может составить ИСО и засвидетельствовать нотариально свою подпись на данном документе, подтверждающем его приоритет на совокупность стилистических особенностей своих произведений. Если рассматривать каждое произведение как творческую переработку ИХС, то стиль становится охраноспособным.

К сожалению, на практике нотариусы очень неохотно совершают необычные, хотя и совершенно легальные нотариальные действия, например, свидетельствование подписи на произвольном документе. В таком случае можно воспользоваться электронной цифровой подписью (ЭЦП), которая, помимо иных сведений, сохраняет дату и время подписания документа, при чем достоверность ЭЦП презюмируется законодательством, что фактически не позволяет оспаривать ее действительность без крайне существенных оснований.

Анализ, проведенный в настоящей статье, позволяет прийти к следующим выводам:

- Действующее законодательство предоставляет правовую охрану самому художественному произведению как результату интеллектуальной деятельности в рамках авторского права, при этом идеи и замыслы не признаются правообъектными и охране не подлежат. В рамках патентного права, напротив, охраняется результат интеллектуальной деятельности в качестве идеи (изобретение). Правовая охрана индивидуального художественного стиля, таким образом, представляет собой частичную рецепцию патентного права в авторское право.

- Охрана индивидуального художественного стиля может осуществляться через придание ему условной объективной формы индивидуально-стилистического описания (ИСО). Рассматривая художественное произведение как продукт творческой переработки индивидуального художественного стиля, составление ИСО, тем самым, воспретит рецепцию данного стиля другими авторами без согласия правообладателя ИСО.

- Учитывая личный характер ИХС, представляется целесообразным законодательно запретить переход исключительного права на ИСО, а равно и признать ИСО недопустимым предметом договора авторского заказа и недопустимым служебным произведением.

\section{ЛИТЕРАТУРА}

1. Гражданский кодекс Российской Федерации (часть четвертая) от 18.12.2006 N230-Ф3 // Собрание законодательства РФ», 25.12.2006, N52 (1 ч.), ст. 5496

2. Большаков В.П. История и теория культуры: учеб. пособие для академического бакалавриата / Л.Ф. Новицкая, К.Ф. Завершинский, В.П. Большаков; под общ. ред. В.П. Большакова.— 2-е изд., перераб. и доп.— М.: Издательство Юрайт, 2018. — 289 с. 
3. Парижская конвенция по охране промышленной собственности» от 20 марта 1883 г., пере-смотренная в Брюсселе 14 декабря 1900 г., в Вашингтоне 2 июня 1911 г., в Гааге 6 ноября 1925 г., в Лондоне 2 июня 1934 г., в Лиссабоне 31 октября 1958 г. и в Стокгольме 14 июля 1967 г. и измененная 2 октября 1979 г. (1979) [Электронный ресурc] // URL: http://docs.cntd.ru/document/1900359 (дата обращения 31.03.2021)

4. Бернская конвенция по охране литературных и художественных произведений от 9 сентября 1886 г., дополненная в Париже 4 мая 1896 г., пересмотренная в Берлине 13 ноября 1908 г., дополнен-ная в Берне 20 марта 1914 г. и пересмотренная в Риме 2 июня 1928 г., в Брюсселе 26 июня 1948 г., в Стокгольме 14 июля 1967 г. и в Париже 24 июля 1971 г., измененная 28 сентября 1979 г. (1979) [Электронный ресурс] // URL: http://docs.cntd.ru/document/1900493 (дата обращения 31.03.2021)

5. Дозорцев В.А. Авторские дела в суде: Научно-практический комментарий. М., 1985. - С. 40-42

6. Гражданское право: учебник / под ред. Е.А. Суханова: В 2 т. Т. 2. М.: БЕК, 1994.— С. 257.

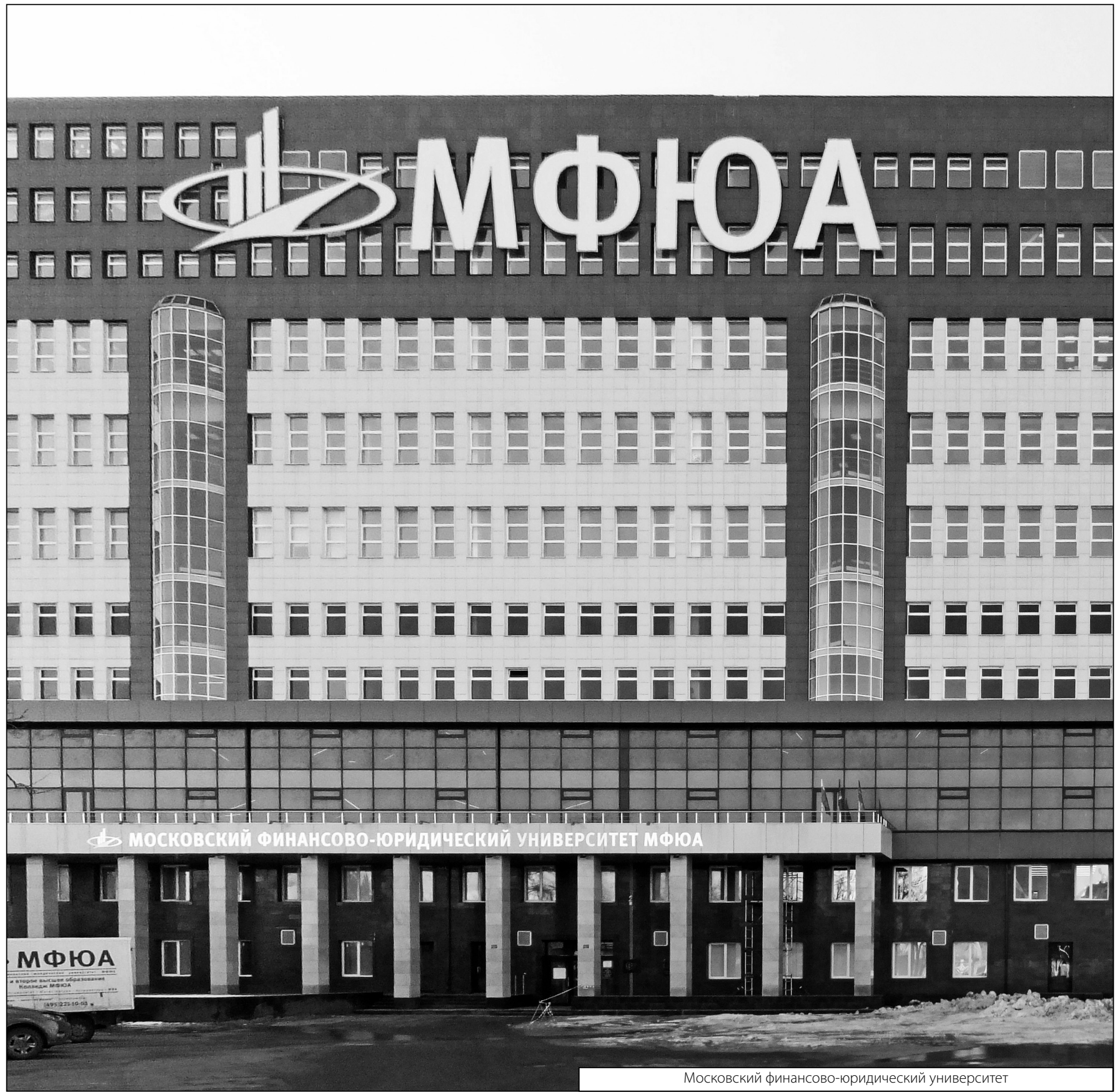

